\title{
The Letter Of The Law: Constraints on architectural form in Japan
}

\section{Tom Daniell}

As exemplified by Tokyo, the Japanese city tends to be seen as an unrestricted laboratory for experiments in urban and architectural form. In reality, like most cities, the shape of Tokyo is influenced and determined by an invisible array of forces and constraints. Many of the city's unusual building profiles are simply the outcome of thoughtless compliance with building codes. Although severely limiting the architect's options, these legal regulations may also be consciously instrumentalized in the design process.

Although the visual incoherence of contemporary urban Japan has many sources, to a large extent it is the result of the firebombing campaigns in the final months of the Second World War. The sheer urgency of providing shelter, with scant resources, produced a haphazard, chaotic condition that became the basic template for future urban growth. This has long been a subject of both criticism and celebration. Despite the nation's rapid economic progress in the postwar decades, Tokyo was widely considered to have serious aesthetic and functional problems. However, a revisionist attitude that saw the disorder as positive and productive soon appeared. As early as the 1960s, architect Kazuo Shinohara asserted that postwar Tokyo had a unique vitality, and the visual chaos should be regarded as a kind of beauty. Shinohara's statements were an epiphany for many architects and thinkers in Japan, and became a theme that he and others elaborated on over the following decades. In a 1981 essay entitled "Towards Architecture," Shinohara described Tokyo as possessing a "progressive anarchy" (he used English for this phrase, in an otherwise Japanese text) that was the source of inspiration for his own architectural design:

No other city has the diversity of buildings that comprise its streets, or the disorder of decorative surface colors and forms on their facades. Chaos is the only appropriate word to describe it. But I do not unconditionally dismiss this as chaos. In essence, chaos contains a portent of ruin. Yet in so many places within this "vast village" of a city before us, the streets are full of "vitality". Tokyo has now become one of the most exciting cities in the world.... In the design of a single building, the method of expressing anarchy as the theme can be established as an architectural logic (Shinohara, 1981: 140-141).

Published together with the essay was a design by Shinohara named the House Under High-Voltage Lines. Paradoxically, the house is a direct manifestation of - and obedient submission to - one of the city's many constraints: specifically,

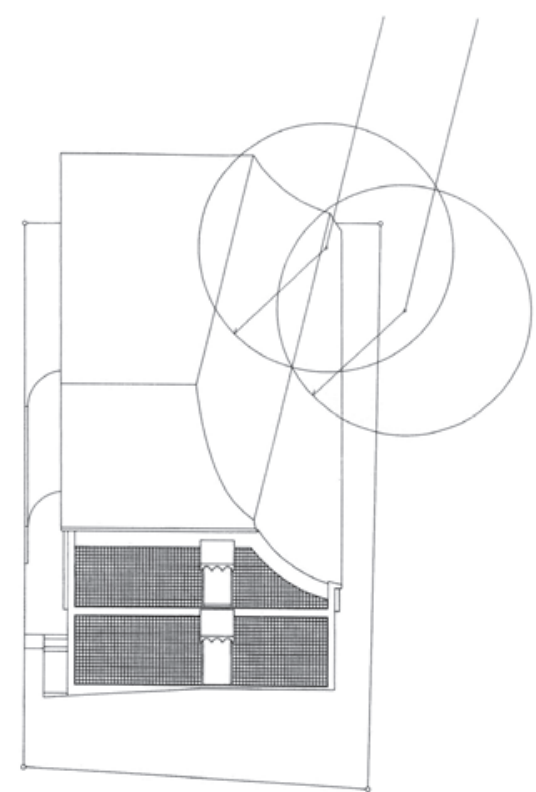

House Under High-Voltage Lines, Kazuo Shinohara, 1981 (courtesy office of Kazuo Shinohara). 


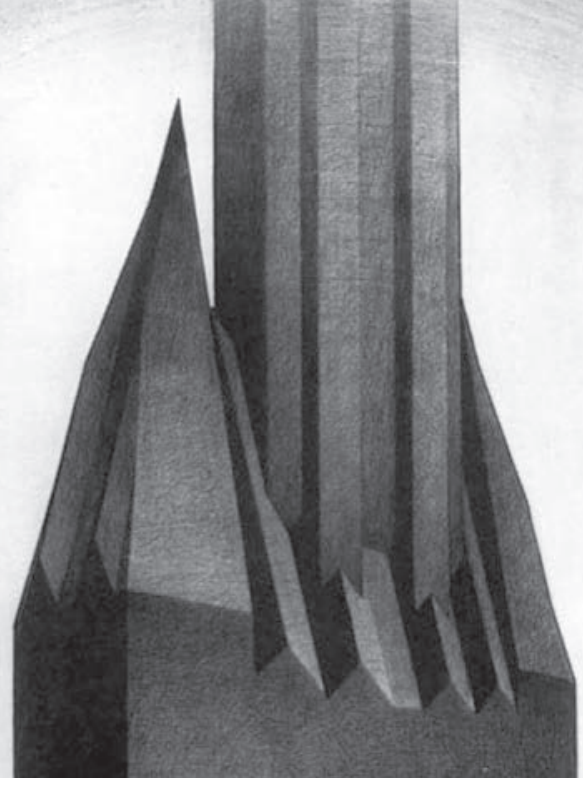

"a representation of the maximum mass..." Hugh Ferriss, 1929.

I. Depending on location, there were five possibilities: one times street width; one and a quarter times street width; one and a half times street width; two times street width; two and a half times street width (Garvin, 2004, n.p.).

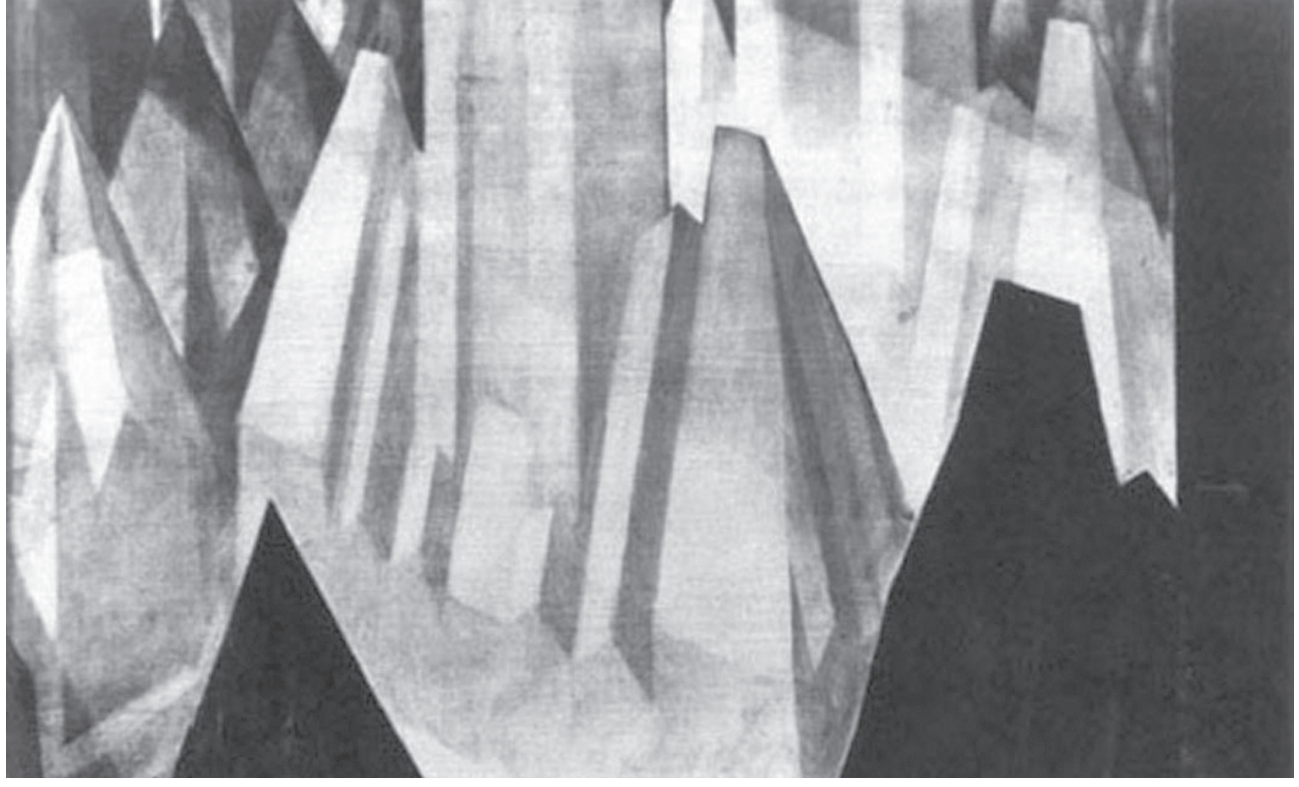

“... over all the blocks of a city." Hugh Ferriss, 1929.

a regulation that stipulates the minimum distance a building must maintain from overhead power lines. This, in effect, defines an invisible cylinder along the axis of each cable, within which it is illegal to build. Shinohara located the nearby power cables, deforming the roof profile, and the interior spaces, in accordance with the code.

This approach to generating architectural form is, of course, reminiscent of a famous set of renderings by New York architect and illustrator Hugh Ferriss. In 1922, Ferriss was commissioned by the architect Harvey Wiley Corbett to draw a sequence of four perspective images, depicting the effects on architectural form of the pioneering 1916 New York City Zoning Resolution. Prior to the enactment of this law, there were no restrictions on the bulk or height of buildings in Manhattan. By forcing building profiles to step back diagonally as they rose vertically, the Zoning Resolution was intended to guarantee a degree of sunlight and air to the lower levels of the buildings and to the streets. The law provided simple formulas that defined maximum building volumes. The entire area of a given plot could be extruded vertically to a height that was a set multiple of the adjacent street's width. ${ }^{1}$ Above this point, the building envelope sloped inward at an angle determined by drawing an imaginary line from this height to the centre of the street below, forming a sloping setback known as a "sky exposure plane". In the middle of each plot, a tower covering no more than a quarter of the site was permitted to rise without any upper limit.

Ferriss' four sketches became the core of his 1929 book, The Metropolis of Tomorrow, which contains many evocative architectural images extrapolated from the legally defined envelopes. Ferriss notes that the Zoning Resolution:

... was based on purely practical consideration. ... The law as a whole was directed to securing an increase in public safety, convenience, efficiency and health. From the viewpoint of Design, it is interesting to recall that the Zoning movement having its genesis in just such considerations as have been mentioned was not at all inspired by concern for its possible effects on Architectural Design (Ferris, 1986 [1929]: 72).

Yet, by defining maximum volumes within a context that implicitly demands maximization, the law had direct and immediate effects on the aesthetics of architectural form. Ferriss first drew the envelope of a single city block: 
... a representation of the maximum mass which, under the Zoning Law, it would be permissible to build over an entire city block.... It must be understood that the mass thus delineated is not an architect's design; it is simply a form which results from legal specifications (Ferris, 1986 [1929]: 74).

He then showed what would happen "if the maximum masses which are permitted by the New York Zoning Law were erected over all the blocks of a city" (Ferris, 1986 [1929]: 82). As required by their clients, the architects of the time did indeed try to achieve maximum usable floor area while complying with the code, but in practice they built ziggurats that only approximated the angled setbacks depicted by Ferriss. The end points of the stepped profiles traced the invisible sky exposure planes.

New York was the first US city to impose zoning laws, but most others soon followed. In each case, local code variations led to differing formal results; a well-known example is the comparatively boxier skyscraper typology of Chicago, the forms of which are equally a product of zoning laws (Willis, 1995). Elsewhere in the world, legislation intended to ensure a fair distribution of natural light and air has given rise to characteristic architectural typologies: urban courtyard blocks, thin modernist slabs, terraced townhouses, low-density suburbia, or the residential complexes of Hong Kong's New Territories that comprise vast podiums supporting multiple residential towers.

In 1961, New York City introduced a new zoning ordinance based on floor area ratios (FAR, the maximum allowable floor area defined as a multiple of the site area). Although no longer mandating pyramidal forms, and indirectly encouraging the design of skyscrapers with straight vertical profiles and street plazas in front, the new code also entailed the first height restrictions ever imposed on Manhattan (albeit parametrically defined). ${ }^{2}$ However, Tokyo currently uses setbacks very similar to the 1916 New York Zoning Resolution. The Japanese system was officially implemented with the enactment of the Building Standards Law in 1950, although it is based on Japanese studies of Western cities that go back more than a century. Having undergone several revisions, the code now comprises detailed regulations for the bulk, height and density of buildings, as well as site coverage, floor area ratios, street setbacks, side-yard widths, structural types, safety and usage. The volumetric controls are known as shasen-seigen, which literally means "diagonal line regulations" (although they are in effect planes rather than lines). Just as in New York, they were not conceived as aesthetic controls, but to prevent buildings from blocking sunlight and air from their neighbours. According to one source, the primary motivation for the shasen is to allow all citizens to hang their laundry in direct sunlight for part of each day (Nakamura, 1992: 85).

There are three basic types of shasen: from the north (kitagawa-shasen), from the road (douro-shasen), and from the adjoining sites (rinchi-shasen). They generally slope at 1:0.6 or 1:1.25 in residential zones, and 1:1.5 in commercial zones. In terms of effect on the built environment, the most important is the north shasen. It starts $5 \mathrm{~m}$ above ground level (in residential areas; it can be up to $10 \mathrm{~m}$ in commercial areas) at the northern site boundary, and then slopes toward the south. Naturally, most sites are not perfectly aligned with the cardinal points, so the north shasen
2. "In New York, the first finite limits on volume (and therefore on height) were imposed in 1961, when the 1916 zoning ordinance received its first major revision ... the FAR formula effectively ended the standard setback massing, not because the new code prohibited it, but because sheer-walled towers in open plazas became more profitable." (Willis, 1995: 14014I).

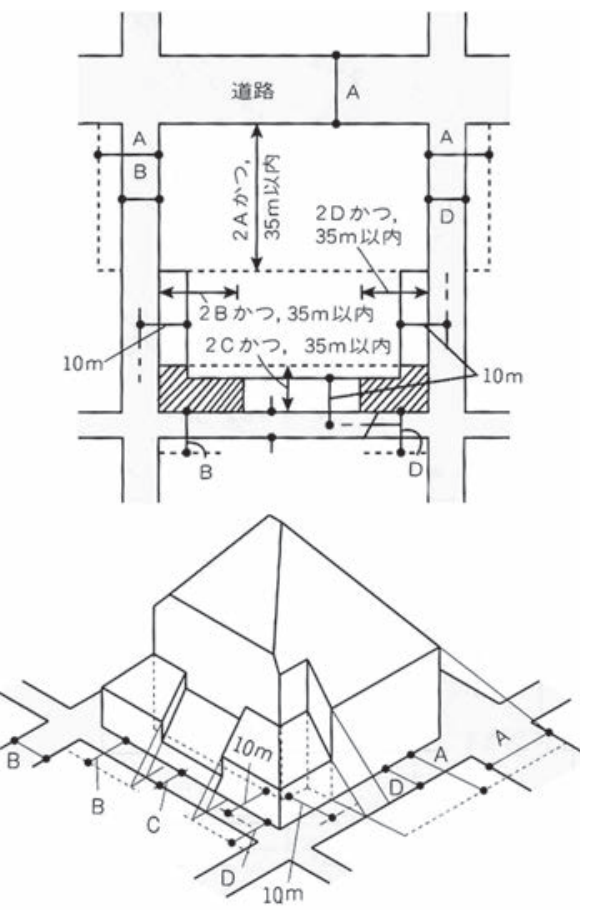

An example of the volumetric modelling required by shasen regulations (diagrams taken from the Building Standards Law Guidebook). 


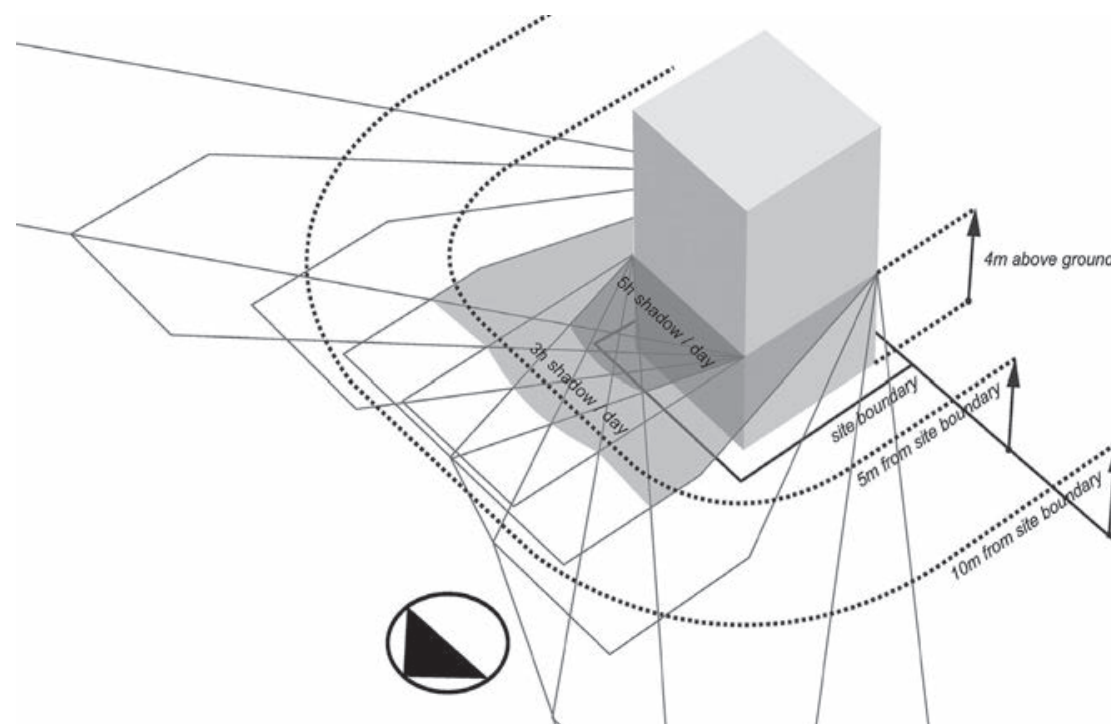

Shadow distribution limits according to the nichiei-kisei regulations (diagram by Tom Daniell).

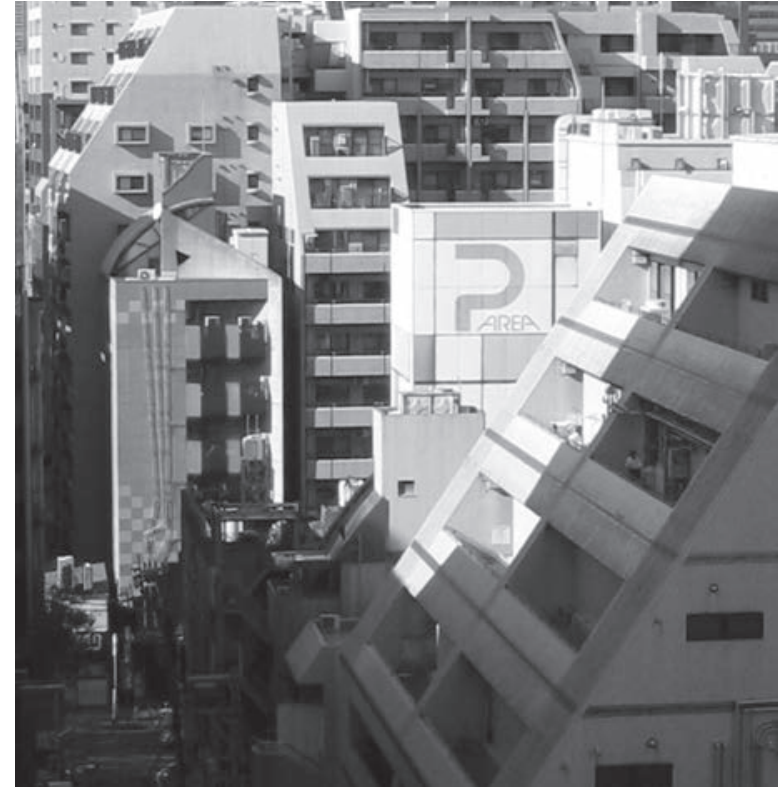

Typical bevelled building forms in Japan (photo by Tom Daniell).

will also have some impact on either the eastern or western boundary. The road shasen starts from ground level at the opposite side of the adjacent streets. The wider the street, the less impact it will have on building form. If the building is set back from its own street boundary, the starting point of the shasen is shifted correspondingly further away on the other side of the street, and it is further affected by irregularities in road widths and intersections. Finally, the adjoining site shasen applies at every non-street boundary. It starts either $20 \mathrm{~m}$ or $31 \mathrm{~m}$ above ground level, and thus is usually irrelevant in residential areas.

While smaller elements such as balustrades and billboards are permitted to project through the shasen, as are penthouse towers of no more than $1 / 8^{\text {th }}$ the building footprint, the Building Standards Law also sets overall maximum building heights (zettai-takasa-no-seigen). The height limit in residential areas is generally $10 \mathrm{~m}$, but above a height of $7 \mathrm{~m}$ (or two storeys, whichever is lower) the shasen are supplemented by additional volumetric controls known as sun-shadow regulations (nichiei-kisei). These place further restrictions on the building volume, according to the amount of shadow it casts between 8am and 4pm (or 9am and $3 \mathrm{pm}$, if it adjoins a road) on the winter solstice. Lines are drawn at $5 \mathrm{~m}$ and at $10 \mathrm{~m}$ from the site boundary line, at a height above the ground plane of $1.5 \mathrm{~m}$ (residential) or $4 \mathrm{~m}$ (commercial). The shadow cast by the building must not exceed theselines formore than a defined time period:usually, morethan 3 hoursofshadow should not pass the $10 \mathrm{~m}$ line, and more than 5 hours of shadow should not pass the $5 \mathrm{~m}$ line. If the shadows exceed these limits, additional chunks must be removed from the building volume - a common cause of irregular building forms in urban areas. To avoid an extended period of reiterated trial-and-error design, it is common for Japanese architects to begin by modelling the allowable building envelope, and then use this as the basis for design.

The limits for total site coverage (kenpei-ritsu) and total floor area (youseki-ritsu) are both given as ratios of the site area. Each district is assigned a pair of numbers that indicate maximum site coverage and floor area as percentages of the total site (e.g. 60/200). However, it is not uncommon for sites to span more than one zoning, in which case the floor area ratios are averaged for the entire site. In commercially zoned districts, it is often impossible to achieve the maximum allowable floor area within the volumetric constraints, so economic pressures mean that the allowable building envelopes are almost always filled. Unlike early $20^{\text {th }}$ century New York, ziggurats are rare; the Japanese preference is to precisely follow the shasen-seigen, producing the ubiquitous wedge-shaped volumes of the Tokyo skyline. Private houses are less noticeably affected by shasen, 
because in residentially zoned districts the floor area ratios are relatively low, and the maximum allowable floor area can be achieved without entirely filling the building envelope. A house that does swell to occupy the allowable volume will usually produce excessive floor area, and a common solution is to insert internal voids or exterior courtyards into the house volume.

Although the code might be expected to cumulatively sculpt a group of buildings on a given city block into a more-or-less coherent overall profile, anomalies in the shasen and other regulations mean that adjacent buildings often appear to be subject to differing sets of laws. In many cases, bizarre building forms are no more,
Below: decoding the effects of shasen regulations (courtesy Yasutaka Yoshimura).

Bottom: decoding the effects of nichi-ei regulations (courtesy Yasutaka Yoshimura).
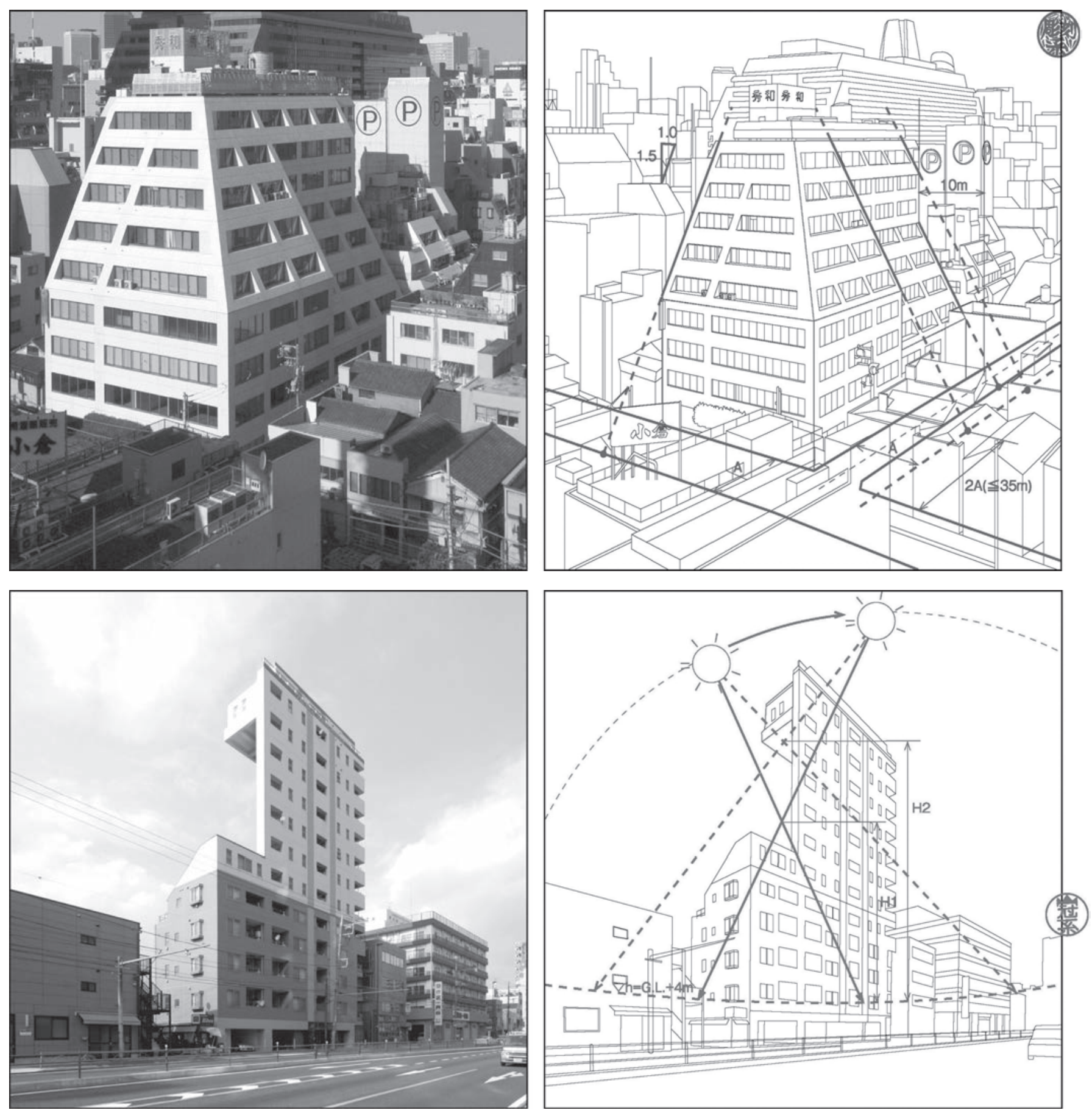
